Article

\title{
The Linkage between Sustainability and Innovation Performance in IT Hardware Sector
}

\author{
Francesca Michelino *, Antonello Cammarano, Andrea Celone and Mauro Caputo \\ Department of Industrial Engineering, University of Salerno, 84084 Fisciano, Italy \\ * Correspondence: fmichelino@unisa.it
}

Received: 14 July 2019; Accepted: 4 August 2019; Published: 7 August 2019

\begin{abstract}
This work investigates the relationship between sustainability and innovation performance. Despite the relevance of the issue, few contributions deepen such a relationship after both a conceptual and a quantitative perspective. Therefore, the aim of this paper is to suggest a measure of sustainability for innovation processes and to define which innovation strategies can lead to more sustainable processes. The role of ambidexterity within the corporate sustainability framework is underlined: Ambidextrous organizations are able to improve the innovation performance and better use their resources, improving the sustainability of research and development (R\&D) processes. By employing patent data and testing the framework on a sample of worldwide top R\&D spending companies in the IT hardware industry, this work suggests which optimal value of ambidexterity will lead to more sustainable innovation. In addition, R\&D processes with non-optimal levels of ambidexterity can be managed in a better way. Indeed, results show the usefulness of open innovation adoption to improve the performance of exploration processes. Moreover, R\&D activities based on a preponderance of exploitation strategies are more sustainable if they fall into technological domains in which the focal company is highly specialized. The work also contributes to the conceptualization of sustainability and to definition of patent-based metrics related to sustainability.
\end{abstract}

Keywords: sustainability; technological strategies; ambidexterity; exploitation vs. exploration; open innovation; specialization; innovation; innovation performance; patent data

\section{Introduction}

Investigating the relationship between sustainability and innovation is a focal topic, in line with the ninth Sustainable Development Goal, which requires the fostering of innovation while ensuring sustainable development. The link between sustainability and innovation is of great importance also because it embraces the whole cycle of a product; from the creative phase [1] to the development of a new product [2] and even during the production process [3], in the supply of after-sales customer services [4], and in the phase of disposal.

The link between sustainability and innovation has already been the subject of scientific discussion [5-8], which, however, has focused only on certain aspects of the relationship and not exhaustively. Indeed, such a linkage is not immediate, and to our knowledge no contribution suggests metrics to measure the relationship between sustainability and innovation performance. This causes difficulties in linking each other and in defining the effects of this linkage.

Therefore, the aim of this work is twofold: (1) Providing a measure of sustainability for innovation processes and (2) defining which innovation strategies are more sustainable, i.e., are capable of producing a sustainable innovation process.

As to the first point, if sustainability is related to the efficient management of scarce and limited resources to achieve positive results, an innovation process can be considered sustainable when knowledge and technological resources are efficiently used to obtain high-quality tangible 
and intangible innovation outputs. For this reason, the authors believe that a measurement system for sustainable innovation should rely on patent data. Indeed, patents provide publicly available, standardized information about the output of technological innovation: High objectivity of patent data is guaranteed by the fact that they are verified by independent third parties (the patent examiner).

With reference to the second point, sustainability is traditionally related to achieving results within the appropriate time but also achieving results continuously over time. In knowledge management studies, such issues are related to exploitation vs. exploration strategies, with the former directly linked to short-term sustainability, whereas the latter is more oriented to long-term sustainable processes. Most authors [9-11] agree that, more than defining a trade-off between exploitation and exploration, both strategies should be pursued at the same time, after an ambidextrous perspective. Therefore, the first research question of this study is:

"Which is the most sustainable mix of exploitation vs. exploration strategies?"

Indeed, authors intend to uncover the most performing value of ambidexterity that allows firms to achieve the highest innovation performance, since the higher the innovation performance, the more sustainable the $R \& D$ effort, given that the consumption of resources will be oriented to the most performing processes, reducing costs, increasing profits, achieving efficiency and effectiveness, reducing waste of resources, minimizing the time to develop products and technologies, and contributing to company survival, consolidation, and growth.

However, companies that perform a variegated set of R\&D processes are not always able to reach optimal levels of ambidexterity This will imply that various R\&D activities will be characterized by lower performance levels, i.e., will be less sustainable in the long term. Specifically, some R\&D projects will be more oriented on exploitation activities, whereas other ones will be featured by relevant shares of exploration. Therefore, a second research question will be:

"Which innovation strategies can mitigate the loss of performance featuring R\&D processes with non-optimal exploitation vs. exploration mix and guarantee acceptable levels of sustainability?"

For instance, many scholars argue that open innovation (OI) strategies allow firms to access new external knowledge, resources, and technology, i.e., perform exploration activities. Hence, OI practices might support firms in achieving sustainable innovation practices in exploration R\&D processes, compensating the loss of performance due to the non-optimal exploitation vs. exploration mix. Indeed, when firms carry out highly explorative R\&D efforts the quality of the results achieved is variable and often unpredictable in the long term.

On the other hand, an excess of exploitation will lead to low performance levels and low quality of innovation output, with few improvements of technologies and products and incremental developments. However, a strong specialization on a specific technical field will compensate the loss of performance, since the R\&D effort will involve R\&D personnel with greater mastery and awareness with a vision on the future of the focal technology or technical domain that will guarantee higher performance and quality of innovation performance and, consequently, more sustainability.

In what follows, the theoretical conceptualization of the linkage between sustainability and innovation is presented and the role of exploitation vs. exploration strategies is analyzed. Thereafter, the methodological framework is illustrated, and results are presented and discussed. Conclusions close the work.

\section{Background}

\subsection{Sustainability and Innovation}

Sustainability and innovation have often been the subject of joint analysis on various topics including: Opportunities for start-ups [1], design and prototyping of new products [2], use of scheduling in production [3], and service innovation [4]. For these reasons, sustainability has been 
defined as a "mother lode of organizational and technological innovations" [5]. However, there is a need to better understand the linkage between sustainability and innovation, and a first literature issue is to define a common point. For example, one of the ways to evaluate innovation is related to the degree of efficiency and effectiveness of innovation. Effectiveness reflects the degree of success of an innovation, while innovation efficiency relates to the effort made to achieve such degree of success [6]. Consequently, effectiveness and efficiency can be considered performance parameters aiming at profit maximization. For instance, efficiency issues are linked to the replacement of obsolete products, the horizontal extension of the product range, or the introduction of technologically better, environmentally friendly, or new products, to the opening of new markets abroad or to new targets in the national context, or to increase market share [12]. Instead, measures of effectiveness could be the average time to develop a new product/service or component, the average number of hours of work needed, the average cost, and the degree of overall final satisfaction [13].

Therefore, sustainability and innovation could be linked by focusing on the performance effects guaranteed by sustainable R\&D processes. Based on all the above considerations, it is clear to understand why the obsolete concept of eco-innovation and eco-efficiency, basically oriented to ecological and green aspects, has slowly evolved into a more complete approach named sustainability-oriented innovation, making intentional changes to processes and/or products to create environmental and social value, but an economic return too [14]. Sustainability-oriented innovation proposes to alleviate the tensions between the company's environmental, social, and financial objectives, which are often at odds with each other. However, beyond the conceptual definition of sustainability, an additional problem found in literature is related to how to measure sustainability. Indeed, various measures have been suggested to analyze the contributions of companies to sustainability, such as those that state that companies contribute to sustainability when the value created exceeds the damage (economic, social, and environmental) caused outside the company, or measure the eco-efficiency, i.e., the creation of the highest possible value in relation to the environmental impact [7]. Another measure, known as "sustainable value added" considers both the efficiency (a relative measure, explained by relationship between the unwanted consequences, e.g., environmental impacts, and the desired ends, e.g., the economic performances) and the effectiveness (an absolute degree of environmental, social, and economic performance) of the use of resources [8]. Therefore, the difficulties in measuring sustainability inevitably determine a significant issue once a scholar intends to evaluate the relationship between sustainability and other topics. To our knowledge, the linkage of sustainability with innovation performance has never been investigated after a quantitative perspective, suggesting metrics to evaluate the effects of such a relationship.

In addition to the concept of profit maximization, sustainability-related aspects are also linked to time-related issues. Indeed, since consumers influence the market with their choices, companies need to learn sustainable consumer behaviors, whereas consumers have to understand sustainable corporate strategies. Consequently, citizens and businesses often prefer immediate economic benefits instead of sustainable long-term benefits [15]. The consumption of goods and services involves individual choices that involve short-term personal interests rather than sustainable long-term common goals. The growth model with a short-term time horizon and individual interest is far from the model of sustainable innovation with a long-term orientation [16]. However, it is important to highlight that an economically viable company must guarantee enough cash flow to guarantee liquidity at any time, while still producing a return above the average for its shareholders. Therefore, a sustainable business can be defined as the ability of companies to respond to their short-term financial needs without compromising their ability to meet their future needs [17]. In other words, sustainability can refer to the company's ability to be profitable not only today but also tomorrow.

The linkage between sustainability and innovation is well represented by the adoption of open innovation (OI) strategies. The optimization of idea generation and product development processes aimed at reducing the waste of knowledge and technological resources is possible, in a large part of cases, by adopting a collaborative and regenerative policy, rather than a competitive and extractive 
one. Indeed, companies are increasing their availability both in cooperation with customers and in adopting a sustainability approach [7], signaling that OI contributes to the hope that large and small companies might benefit from cost savings and environmental benefits deriving from sharing sustainability-oriented innovations [18,19]. Value creation and OI can be oriented towards the creation of a new product designed and built with high sustainability criteria. The practical implications are represented in the opportunity for companies to co-create value by co-operating in networks and managing sustainable innovative projects [20].

\subsection{Ambidexterity, Exploitation, and Exploration}

To investigate the relationship between sustainability and innovation, it is useful to consider the technological strategies that companies can select to carry out R\&D efforts. Specifically, the trade-off between exploitation and exploration is certainly a focal issue for sustainable innovation strategies.

"Exploration" means a strategic practice aimed at finding new domains of knowledge through basic research, research, and experimentation, while the so-called "exploitation" refers to the use of skills and knowledge already present in a company, through activities such as standardization and optimization of the processes, upscaling, and refinement, [21]. The exploration of new possibilities and ideas is based on distant research and linked to new experiments, accepting the idea of taking risks, but in order to create new capacities [22] or produce new knowledge [23]. Such a new body of knowledge will serve as a seed for future technological development [24] moving on to a different technological trajectory [25] and aiming to enter new domains of the product market [26] to have a long-term growth horizon. Instead, exploitation activities allow companies to achieve economies of scale and short-term results [22]. They are based on local search and follow the current technological trajectories, improving the existing knowledge domains of the product market [26].

Internal development is therefore the most common practice for obtaining exploitation. A large literature confirms instead that the use of open innovation activities is motivated by access to new knowledge from the outside $[27,28]$. Therefore, an open strategy is preferred to a closed one when new knowledge domains should be explored. Moreover, while exploration and exploitation are mutually exclusive within a single technological field, they can coexist between different domains; therefore, high levels of exploitation in a specific area can also correspond to high levels of exploration in others and vice versa [29].

In the context of exploitation, it is also interesting to try to understand the different degree of exploitation of existing knowledge. Indeed, differences in the depth of research lead to varying degrees of confidence with the knowledge in question. Therefore, companies can expand their knowledge, vertically pursuing specialization, or horizontally, following diversification [30,31]. For example, with specialization strategies companies focus on a narrow area of knowledge, activity, or skill $[32,33]$, reducing the probability of errors, even if undertaking excessive exploitation phases could be wrong in the future. Specialization, therefore, makes research more reliable and allows companies to better distinguish elements of knowledge of poor value from precious ones and to develop connections between them [34]. On the other hand, companies can think of diversifying to extend their business activities into additional fields [35,36], seeking and accumulating knowledge with potential applications in multiple product market domains [37]. The technological portfolios in which knowledge is spread over many technical fields are considered to be symptoms of higher levels of technological diversification [38].

\subsection{Sustainability and Exploitation vs. Exploration}

Policies that consider both the time factor and the sustainability of the company are linked to the company's ability to have the strength to explore new horizons of knowledge, but at the same time to economically exploit the skills and knowledge already acquired. For example, there are also theoretical arguments that support the idea that the concept of exploitation can be used within the corporate sustainability framework. From the perspective of sustainable exploitation 
practices, organizations should achieve continuous incremental improvements to effectively generate a material, water, and energy use reduction and productivity improvements. Consequently, one of the main premises of sustainability exploitation practices is to improve sustainability performance and, simultaneously, increase competitiveness [9]. Furthermore, sustainability and exploitation strategies can be associated with the increase of organizational ability to apply cost-effective solutions to solve sustainability problems [10].

Organizations, however, also need new knowledge for innovation and exploration of the unknown to contribute to sustainable business management. Sustainable exploration practices reflect process innovation, product innovation, and sustainability-oriented learning; from a production point of view, process innovations in terms of new sustainable solutions can be associated with exploring sustainability.

In contrast to the perspective of the value chain function that usually deals with exploration and exploitation as dichotomous measures, the domain of knowledge makes exploration and exploitation operational as a continuous measure along one of the three dimensions of the space of knowledge: cognitive, temporal, and/or spatial [11]. In particular, the exploitation of sustainability implies local research that is based on the existing sustainability capabilities of an organization, while the exploration of sustainability involves more distant research for new features or even the development of new organizational mental models.

A management aimed at using both practices (exploration and exploitation) is called "ambidextrous". The organizational ambidexterity arises in the ambit of the organization of the company, to then extend to the field of innovation and the management of corporate strategies [39]. Being an interdisciplinary theory that, consequently, can be applied to a wide range of sectors, it is possible to try to understand the impacts in the context of sustainability from different points of view. From the point of view of stakeholders, for example, sustainability requires the identification of existing stakeholders, the assessment of their needs and the exploration of their new needs. About process management, on the other hand, a sustainable company should tend to continuously improve its existing processes and, at the same time, explore new ways to improve them. From the point of view of product and service design, sustainability requires incremental improvements for existing products and services and the search for opportunities for the development of new products and services. In relation to learning, a sustainable company must train and frequently update the current skills of employees and at the same time develop new knowledge.

Research on organizational ambidexterity is characterized by the evaluation of the balance between exploration and exploitation, which is particularly advantageous for companies focused on sustainable practices [40]. The exploratory approach can facilitate the creation of value while ensuring the acquisition of value [29]. But companies that inadequately seek exploration can waste economic resources on experimentation without obtaining many benefits, while companies that pursue exploitation in an inefficient manner may depend excessively on existing resources, thus remaining vulnerable to environmental changes [41]. Therefore, companies able to dynamically balance exploration and exploitation can survive and prosper both short and long term, making themselves sustainable.

\section{Materials and Methods}

\subsection{Data Sample Definition}

Data were extracted from the 2011 PATSTAT database through a PHP-based software. For comparability reasons, the analysis was confined only to filings recorded in the European Patent Office (EPO), excluding national patent offices. Both priorities actually claimed and first granted patent applications potentially claimable were included, in order to consider both high-value patents $[42,43]$ and less-valuable applications.

The devised framework was applied to patents filed in 2003 by 65 worldwide top R\&D spending companies in the IT hardware industry. The year of analysis was selected depending on the need of evaluating technological quality through an ex-post indicator: Data from 2004 to 2011 were employed 
to detect forward citations. The selection of the sector derives from the fact that patents are widely used in this sector as a means of appropriation of intellectual property.

Companies were sampled from The EU Industrial RED Investment Scoreboard and searched in PATSTAT applicant table trough the PHP application, also searching for further information on Google in order to reduce issues related to name disambiguation and typing errors of applicant names within PATSTAT.

A total number of 3744 patents was detected.

\subsection{Variable Definition}

Different variables were included in the model. First, the exploration vs. exploitation strategy was defined at the knowledge domain level—where such strategies are mutually exclusive-and then the mix of strategies was analyzed at the patent level, where the strategies may coexist [29].

Sustainability is proxied with the technological quality of the patent. Indeed, if the R\&D effort put to develop a patented technology results in a high-quality application, the process can be considered as effective and, therefore, sustainable.

Lastly, two other variables were included to detect innovation strategies that can be pursued to increase sustainability when a non-optimal mix of exploration and exploitation is found: Open innovation and specialization.

\subsubsection{Exploitation vs. Exploration}

In line with literature [44,45], authors employed Cooperative Patent Classification (CPC) codes to operationalize knowledge domains. Each CPC code consists of a five-levels hierarchical symbol: In order to study knowledge domains, the fourth-level code was used [46].

Most authors agree that knowledge rapidly evolves and firms can lose their technical skills if they do not continuously exploit a technological field [38,47-50]. Therefore, not all the patents owned by a firm in year $t$ actually contribute to the stock of knowledge for the year. While the term of the legal patent protection is quite long, according to the aforementioned studies the period during which experience accumulated in a knowledge domain is employable $\left(t_{E X P E R}\right)$ does not exceed five years.

Furthermore, an exploration period ( $\left.t_{E X P L O R}\right)$ was considered: Indeed, from the first time a specific knowledge domain is explored, some time is needed to completely master the technological field. Some authors [22] define a three-year period for $t_{\text {EXPLOR }}$.

Therefore, for each company, CPC codes disclosed in patent applications filed at time $t$ were labelled as follows:

$$
C P C_{i}(t)=\left\{\begin{array}{c}
\text { exploitative, if present in a firm's patent from } t-t_{E X P E R} \text { to } t-t_{E X P L O R} \\
\text { explorative, otherwise. }
\end{array}\right.
$$

Actually, all the knowledge included in applications filed before $t-t_{\text {EXPER }}$ is excluded by the stock of knowledge, being obsolete. Moreover, knowledge generated after $t-t_{E X P L O R}$ in year $t$ is still at an exploration phase. Consistently, CPC codes were labelled as explorative when the first patent application reporting such code was deposited by the focal firm after $t-t_{E X P L O R}$.

For the purposes of this work, the two time periods were reduced in order to consider the peculiarities of the IT hardware sector: Shorter product life cycle, fast development pace, and design modularity [51]. Therefore, three years was set as the experience period and two years for the exploration period. Finally, considering $t=2003$ as the year of analysis:

$$
C P C_{i}(t)=\left\{\begin{array}{c}
\text { exploitative, if present in a firm's patent from } 2000 \text { to } 2001 \\
\text { explorative, otherwise. }
\end{array}\right.
$$


Once the strategy within each technological field was defined in each patent, the ratio of CPC codes in exploration phase on the total number of codes in the document was calculated. Therefore, at the patent level, exploration and exploitation are two percentage variables whose sum equals one:

$$
\begin{gathered}
\text { Exploration }=\frac{\text { No. of CPC codes in the exploration phase }}{\text { Total no. of CPC codes in the patent document }} \times 100 \\
\text { Exploitation }=1-\text { Exploration. }
\end{gathered}
$$

\subsubsection{Technological Quality}

Consistently with literature [52-58], the technological quality of the patent was assessed with the forward citations received from the patent. In order to have a reliable indicator, self-citations were excluded, i.e., only citations received from external parties are considered. Furthermore, in order to ensure consistency, the analysis was confined to citation received from patents filed at the EPO, since the propensity to cite prior art varies among offices [59]. Therefore, technological quality was a count variable:

Technological quality $=$ No. of forward citations received by the patent at the EPO, excluding self citations.

\subsubsection{Open Innovation}

Open innovation is analyzed in its inbound dimension, by defining the affiliation of the resources that took part in the development process. Two different categories of patents can be considered as deriving from open innovation processes [60]:

- patents with more than one assignee, when two or more organizations jointly developed a technology and therefore shared the intellectual property;

- patents with only one assignee but with some inventors not belonging to it: Here, external inventors took part to the development process without sharing the intellectual property with the focal company, who remained the only assignee.

Therefore, two steps were followed to define "open" patents. First, if two or more applicants were found in the assignee field, the patent could be considered as a co-patent, consistent with many literature contributions [61,62]. Second, if only one applicant was found in the assignee field, all the inventors' affiliations were detected: If any inventor found in the application did not belong to the focal firm, the patent was considered as deriving from an R\&D outsourcing process.

Both these categories define an open patent; therefore, a dummy variable was defined:

Open innovation

$=\left\{\begin{array}{c}1 \text { if there are either more assignees or inventors not belonging to the only assignee } \\ 0 \text { if there is only one assignee and all inventors belong to the only assignee. }\end{array}\right.$

\subsubsection{Specialization}

Specialization is considered to analyze how much the company concentrates on specific knowledge domains. Actually, not all technological fields are equally important for a firm, which typically strongly focuses on a limited number of them, which constitute its core business, where other knowledge domains can be considered as peripherical. High specialization is obtained when most R\&D efforts of the company are focused on a few technological fields. In literature, a similar concept is expressed by the so called technological familiarity: A component is familiar to the firm when it has been recently and frequently used $[49,63]$. 
Therefore, for each technological field, specialization was assessed by dividing the number of patents disclosing the $C P C$ code by the total amount of patent applications within the company:

$$
\text { Specialization }_{C P C}=\frac{\text { No. of patents disclosing the CPC }}{\text { Total no. of patent documents }} \times 100 .
$$

Thereafter, specialization of a patent was calculated as the average value of specialization in its different codes [64]:

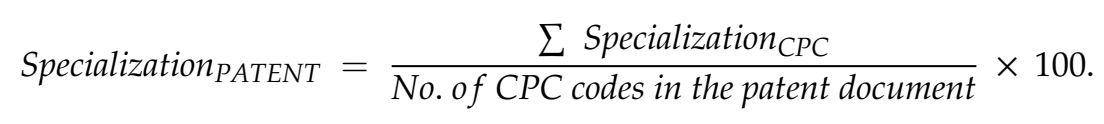

\subsection{Statistical Methods}

Quadratic regression was used to evaluate whether, how, and to what extent technological quality is influenced by the exploitation vs. exploration strategy, i.e., which is the optimal mix of exploitation and exploration that provides the maximum value of quality. Thereafter, linear regressions were used to evaluate whether, how, and to what extent the use of open innovation and the specialization in core technological fields can increase the level of quality, even when a non-optimal mix of exploitation and exploration is adopted.

\section{Results}

In Table 1 the description of the sample is provided. Almost two thirds of the analyzed patents are developed pursuing a pure exploitation strategy, i.e., all the $C P C$ codes reported in the patent document were already present in applications filed in the three previous years. Indeed, the average value of exploration was 0.2 , meaning that on average only two knowledge domains out of 10 are new for the firm. The patents developed with the contribution of third parties were $17 \%$ of the total sample: The great majority $(603,16 \%)$ was obtained with R\&D outsourcing, while the role of joint development was negligible. This means that the companies in the sample prefer to keep internally the intellectual property even when they apply OI practices. Almost all the sample of patents had values of specialization higher than zero, but the average level of specialization was not very high, meaning that, even in almost any patent developed some CPC codes are "core" for the company, a high level of diversification, with many peripheral technological domains, was observed. Lastly, almost all the patents in the sample had at least one forward citation, with an average value of about 10 citations per patent.

Table 1. Sample description.

\begin{tabular}{cc}
\hline Variable & Value \\
\hline Number of companies & 65 \\
Number of patents 2003 (unit of analysis) & 3744 \\
Number (\%) of patents with exploration & $1058(28.3 \%)$ \\
avg. exploration & 0.20 \\
Number (\%) of patents with open innovation & $635(17.0 \%)$ \\
Number (\%) of patents with specialization & $3604(96.3 \%)$ \\
avg. specialization & 0.07 \\
Number (\%) of patents with forward citations & $3386(90.4 \%)$ \\
avg. \# forward citations & 9.93 \\
\hline
\end{tabular}

Table 2 shows the results of regression of the number of forward citations with respect to exploration. Results show that the linear coefficient was positive, whereas the quadratic one was negative, suggesting an inverted U-shape trend. Given that exploitation was defined as 1 - exploration, the result suggests that a balanced mix of exploration and exploitation provides higher technological quality than a pure exploration or a pure exploitation strategy. 
Table 2. Regression: Total sample.

\begin{tabular}{cccc}
\hline Dependent Variable: & Adj. R-Square & F & Sig. \\
\hline Number of forward citations & 0.008 & 15.821 & 0.000 \\
\hline Covariates: & B & $\mathbf{t}$ & Sig. \\
\hline (constant) & 9.825 & 32.930 & 0.000 \\
exploration & 14.904 & 4.818 & 0.000 \\
exploration $^{2}$ & -17.460 & -5.362 & 0.000 \\
\hline
\end{tabular}

The results are also shown in Figure 1, where it is possible to see that the maximum level of expected technological quality was obtained for a mix of exploration vs. exploitation around $40 \%-60 \%$.

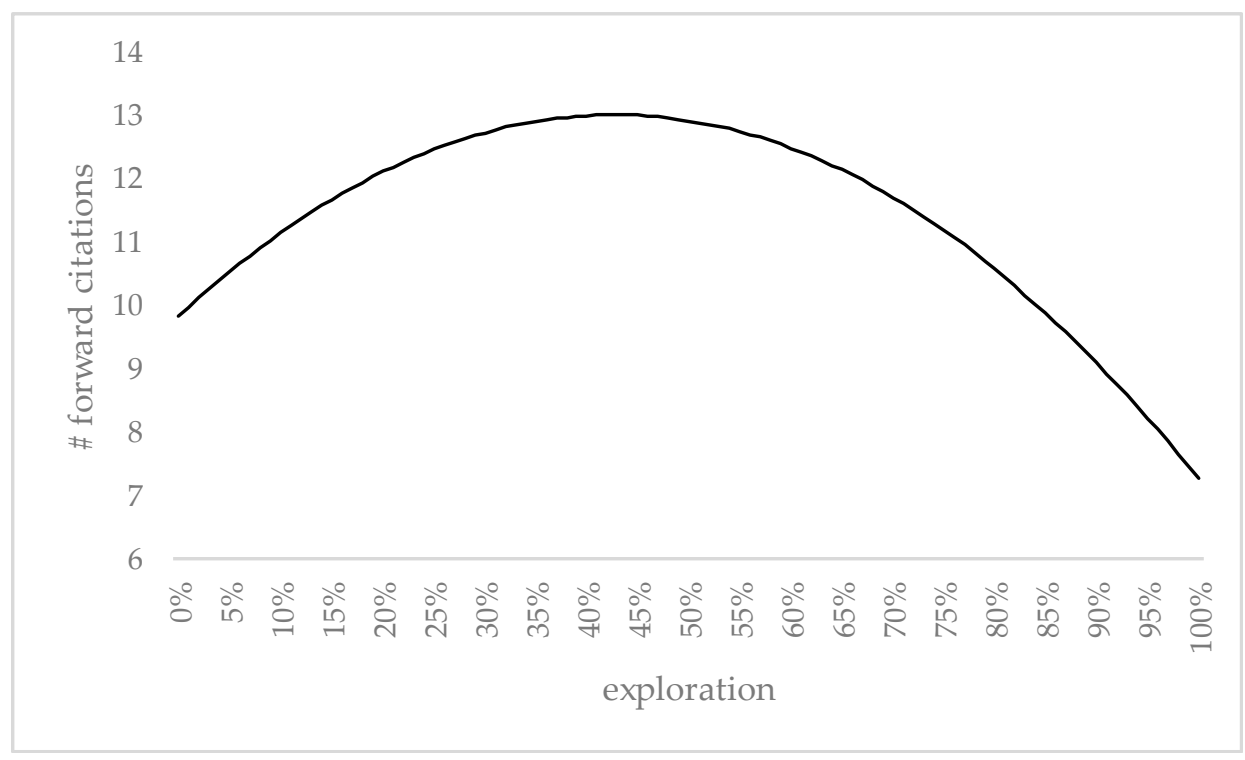

Figure 1. Number of forward citations trend with respect to exploration.

In order to evaluate whether the recourse to OI enhances technological quality when exploration strategies are pursued, in Table 3 regression results are obtained by filtering only patents which actually are in exploration (1058 out of 3744). In this case, even if technological quality decreased with the level of exploration, the recourse to OI practices was positively linked to the number of forward citations received.

Table 3. Regression: only patents in exploration.

\begin{tabular}{cccc}
\hline Dependent Variable: & Adj. R-Square & F & Sig. \\
\hline Number of forward citations & 0.016 & 9.612 & 0.000 \\
\hline Covariates: & B & $\mathbf{t}$ & Sig. \\
\hline (constant) & 15.314 & 10.150 & 0.000 \\
exploration & -8.316 & -4.153 & 0.000 \\
open innovation & 2.818 & 2.005 & 0.045 \\
\hline
\end{tabular}

The results are also shown in Figure 2, where it is possible to observe that, for any level of exploration, the technological quality expected for patents developed in an open context was higher than that in a closed one. 


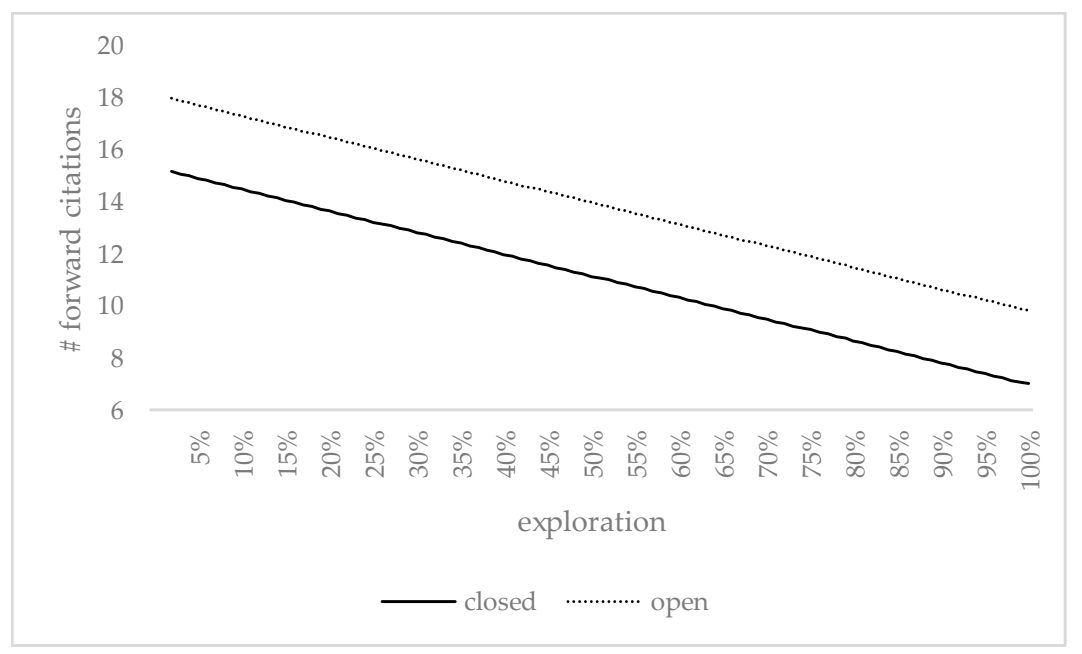

Figure 2. Number of forward citations trend with respect to exploration in closed and open conditions.

In order to evaluate whether higher specialization enhances technological quality when exploitation strategies are pursued, in Table 4, regression results were obtained by filtering only patents which actually were in exploitation (3272 out of 3744). Even if the level of technological quality decreased with exploitation, specialization was positively associated with the number of citations received.

Table 4. Regression: Only patents in exploitation.

\begin{tabular}{cccc}
\hline Dependent Variable: & Adj. R-Square & F & Sig. \\
\hline Number of forward citations & 0.009 & 16.239 & 0.000 \\
\hline Covariates: & $\mathbf{B}$ & $\mathbf{t}$ & Sig. \\
\hline (constant) & 15.606 & 11.118 & 0.000 \\
exploitation & -6.478 & -4.308 & 0.000 \\
specialization & 8.628 & 4.095 & 0.000 \\
\hline
\end{tabular}

The results are also shown in Figure 3, where it is possible to observe that, for any level of exploitation, the higher the level of specialization, the higher the expected technological quality.

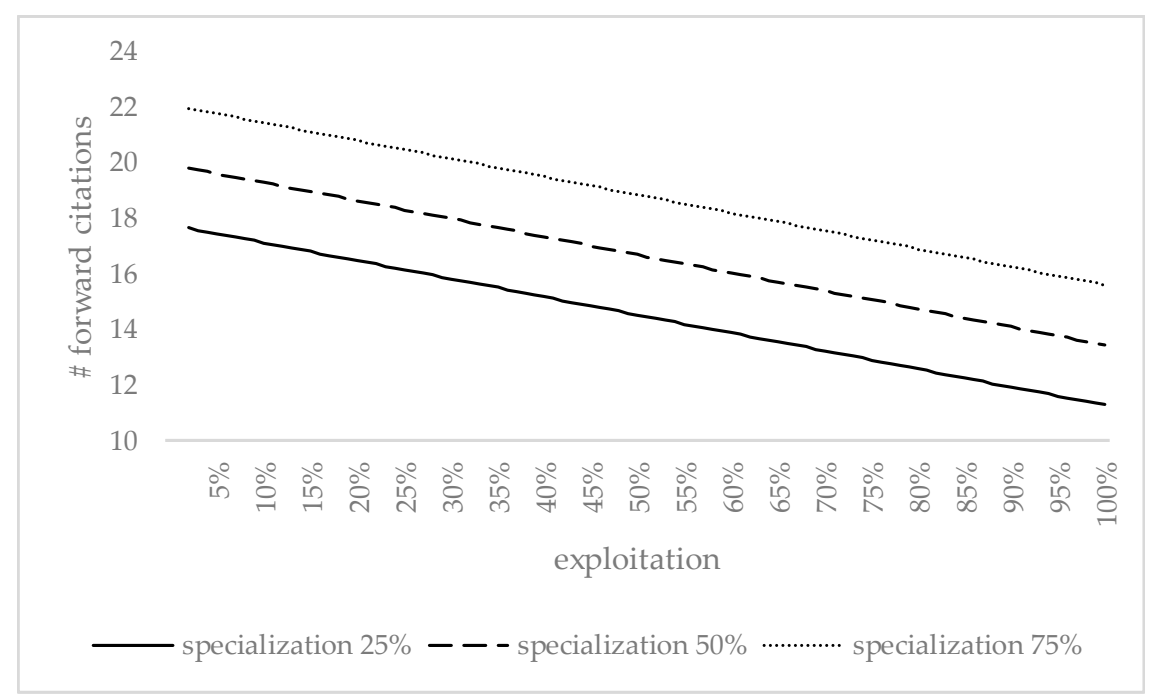

Figure 3. Number of forward citations trend with respect to exploitation with different levels of specialization. 


\section{Discussion}

The obtained results allow us to answer the two research questions.

"Which is the most sustainable mix of exploitation vs. exploration strategies?"

Results show that, in order to obtain highly cited patent documents, the R\&D effort of companies should include both already exploited and still unexplored knowledge domains, i.e., firms should adopt an ambidextrous strategy. The optimal mix obtained was around $60 \%$ vs. $40 \%$ : Highest levels of technological quality when six out of 10 CPC codes included in the patent were already present in previous applications, whereas the other four were new to the firm.

Consistently with literature [41], a balanced mix of such strategies is more sustainable because benefits of both can be pursued, avoiding short-terms traps related to exploitation, but also mitigating the high risks linked to exploration. It can be argued that if exploitation provides sustainability in terms of efficient use of current knowledge resources, exploration lays the foundations for future competitive advantage, sustainable in the long term.

"Which innovation strategies can mitigate the loss of performance featuring R\&D processes with non-optimal exploitation vs. exploration mix and guarantee acceptable levels of sustainability?"

Two different results were obtained when the mix was unbalanced towards exploration or towards exploitation. In the first case, a relevant role is played by OI, which enhances technological quality. The result is not surprising: If the knowledge domains included in the R\&D effort are new to the firm, the presence of third parties—which probably master such knowledge—allows to overcome the difficulties of the company in exploring unknown domains [7]. The recourse to exploration signals the willingness to pursue long-term goals, with all the risks and costs that such strategy implies. However, by involving external actors, risks costs and time can significantly decrease thanks to the body of knowledge provided by such players. Notably, the leading companies in the IT hardware industry adopt inbound open practices that still allow them to maintain all the intellectual property inside the firm (i.e., R\&D outsourcing rather that joint development), in order to guaranteeing sustainable competitive advantage.

On the other side, when exploitation is prevalent, higher levels of technological quality are obtained if specialization is pursued [32,33]. This means that if R\&D efforts are strongly specialized on specific knowledge domains, the short-term traps of exploitation are mitigated. By concentrating on few core domains, the level of mastery and awareness of R\&D personnel increases and future trends for such core technologies can be forecasted, thus ensuring long-term sustainability.

\section{Conclusions}

The work proposes a conceptualization of sustainability in innovation processes through the use of technological quality of patents. Indeed, if the R\&D effort put to develop a patented technology results in a high-quality application, the process can be considered as effective and, therefore, sustainable. Moreover, technological strategies for pursuing sustainable innovation processes are analyzed. In particular, the role of ambidexterity, open innovation, and specialization is investigated. The analysis demonstrates that specific levels of ambidexterity will imply optimization of R\&D efforts and resources and, consequently, more sustainability. Additionally, sustainable innovation will also be achieved within non-optimal levels of ambidexterity by engaging external actors during explorative activities or exploiting the competencies within the technological areas in which the focal company is highly specialized.

The conceptualization of the linkage between sustainability and innovation processes contributes to both literature on sustainability measurement in an industrial context and to theory on innovation management and innovation performances. From a managerial perspective, the paper suggests the optimal levels of exploitation and exploration that, at least in the selected industry, allow to both reuse actual knowledge and explore new technological fields, in order to gain efficiency and effectiveness. 
As the paper is based on patent data, a clear limitation of the work is that the results are not generalizable to industries were patents are not used as a means of appropriation of innovation. At the moment, the work illustrates results for the IT hardware industry, but future works will be addressed to enlarging the sample of companies and considering other R\&D-intense industries. In particular, an interesting case could be represented by bio-pharmaceutic companies, where patents play as relevant a role as in IT hardware, but other features-such as development pace-are very different. From the comparison of the two industries, more general results can be obtained. On the other side, in other industries where patents are not used, different metrics for sustainability of innovation should be developed, based on different forms of intellectual property rights, such as trademarks or copyrights.

Future research directions will be also addressed to enlarge the time horizon as to both technological strategies and innovation performances, as to define long-term effects. Moreover, other patent-based metrics - such as patent family generation or renewal fees payment-will be added in order to better operationalize sustainable innovation.

Author Contributions: Conceptualization, F.M., A.C. (Antonello Cammarano), A.C. (Andrea Celone), and M.C.; methodology, A.C. (Antonello Cammarano); validation, F.M. and A.C. (Andrea Celone); formal analysis, F.M. and A.C. (Andrea Celone); data curation, F.M. and A.C. (Antonello Cammarano); writing-original draft preparation, F.M., A.C. (Antonello Cammarano), and A.C. (Andrea Celone); writing-review and editing, F.M., A.C. (Antonello Cammarano), and A.C. (Andrea Celone); supervision, M.C.; project administration, M.C.

Funding: This research received no external funding.

Conflicts of Interest: The authors declare no conflict of interest.

\section{References}

1. Cappa, F.; Del Sette, F.; Hayes, D.; Rosso, F. How to Deliver Open Sustainable Innovation: An Integrated Approach for a Sustainable Marketable Product. Sustainability 2016, 8, 1341. [CrossRef]

2. Rupo, D.; Perano, M.; Centorrino, G.; Vargas-Sanchez, A. A Framework Based on Sustainability, Open Innovation, and Value Cocreation Paradigms-A Case in an Italian Maritime Cluster. Sustainability 2018, 10, 729. [CrossRef]

3. Shim, S.O.; Park, K.; Choi, S. Innovative Production Scheduling with Customer Satisfaction Based Measurement for the Sustainability of Manufacturing Firms. Sustainability 2017, 9, 2249. [CrossRef]

4. Calabrese, A.; Castaldi, C.; Forte, G.; Levialdi, N.G. Sustainability-oriented Service Innovation: An emerging research field. J. Clean. Prod. 2018, 193, 533-548. [CrossRef]

5. Nidumolu, R.; Prahalad, C.K.; Rangaswami, M.R. Why sustainability is now the key driver of innovation. Harv. Bus. Rev. 2009, 87, 56-64.

6. Lyver, M.J.; Lu, T.J. Sustaining Innovation Performance in SMEs: Exploring the Roles of Strategic Entrepreneurship and IT Capabilities. Sustainability 2018, 10, 442. [CrossRef]

7. Arcese, G.; Flammini, S.; Lucchetti, M.C.; Martucci, O. Evidence and Experience of Open Sustainability Innovation Practices in the Food Sector. Sustainability 2015, 7, 8067-8090. [CrossRef]

8. Figge, F.; Hahn, T. Sustainable Value Added-measuring corporate contributions to sustainability beyond eco-efficiency. Ecol. Econ. 2004, 48, 173-187. [CrossRef]

9. Schaltegger, S.; Wagner, M. Integrative management of sustainability performance, measurement and reporting. IJAAPE 2006, 3, 1-19. [CrossRef]

10. Maletič, M.; Maletič, D.; Dahlgaard, J.J.; Dahlgaard-Park, S.M.; Gomiscek, B. Sustainability exploration and sustainability exploitation: From a literature review towards a conceptual framework. J. Clean. Prod. 2014, 79, 182-194. [CrossRef]

11. Li, Y.; Vanhaverbeke, W.; Schoenmakers, W. Exploration and Exploitation in Innovation: Reframing the Interpretation. Creat. Innov. Manag. 2008, 17, 107-126. [CrossRef]

12. OECD-EUROSTAT. The Measurement of Scientific and Technological Activities. Proposed Guidelines for Collecting and Interpreting Technological Data (Oslo Manual), 2nd ed.; OECD: Paris, France, 1997.

13. Alegre, J.; Lapiedra, R.; Chiva, R. A measurement scale for product innovation performance. Eur. J. Int. Manag. 2006, 9, 333-346. [CrossRef] 
14. Loredo, E.; Lopez-Mielgo, N.; Pineiro-Villaverde, G.; García-Álvarez, M.T. Utilities: Innovation and Sustainability. Sustainability 2019, 11, 1085. [CrossRef]

15. Hofstede, G. Culture's Consequences, 1st ed.; Sage: Beverly Hills, CA, USA, 1980.

16. Lee, S.; Workman, J.; Jung, K. Perception of Time, Creative Attitudes, and Adoption of Innovations: A Cross-Cultural Study from Chinese and US College Students. Sustainability 2016, 8, 1193. [CrossRef]

17. Kashan, A.J.; Mohannak, K.; Perano, M.; Casali, G.L. A Discovery of Multiple Levels of Open Innovation in Understanding the Economic Sustainability. A Case Study in the Manufacturing Industry. Sustainability 2018, 10, 4652. [CrossRef]

18. Belz, F.M.; Peattie, K. Sustainability Marketing: A Global Perspective, 1st ed.; Wiley: Hoboken, NJ, USA, 2009.

19. Michelino, F.; Lamberti, E.; Cammarano, A.; Caputo, M. Open Innovation in the Pharmaceutical Industry: An Empirical Analysis on Context Features, Internal R\&D, and Financial Performances. IEEE Trans. Eng. Manag. 2015, 62, 421-435.

20. Monteiro, P.; De Noronha, T.; Neto, P. A Differentiation Framework for Maritime Clusters: Comparisons across Europe. Sustainability 2013, 5, 4076-4105. [CrossRef]

21. March, J. Exploration and exploitation in organizational learning. Organ. Sci. 1991, 2, 71-87. [CrossRef]

22. Belderbos, R.; Faems, D.; Leten, B.; Van Looy, B. Technological activities and their impact on the financial performance of the firm: Exploitation and exploration within and between firms. J. Prod. Innov. Manag. 2010, 27, 869-882. [CrossRef]

23. Miner, A.S.; Bassoff, P.; Moorman, C. Organizational improvisation and learning: A field study. Adm. Sci. $Q$. 2001, 46, 304-337. [CrossRef]

24. Miller, D.J.; Fern, M.J.; Cardinal, L.B. The use of knowledge for technological innovation within diversified firms. Acad. Manag. J. 2007, 50, 308-326. [CrossRef]

25. Benner, M.J.; Tushman, M.L. Process management and technological innovation: A longitudinal study of the photography and paint industries. Adm. Sci. Q. 2002, 47, 676-706. [CrossRef]

26. He, Z.L.; Wong, P.K. Exploration vs. exploitation: An empirical test of the ambidexterity hypothesis. Organ. Sci. 2004, 15, 481-494. [CrossRef]

27. Karamanos, A.G. Leveraging Micro-and Macro-Structures of Embeddedness in Alliance Networks for Exploratory Innovation in Biotechnology. $R$ D Manag. 2012, 42, 71-89. [CrossRef]

28. Cappa, F.; Rosso, F.; Hayes, D. Monetary and Social Rewards for Crowdsourcing. Sustainability 2019, 11, 2834. [CrossRef]

29. Gupta, A.K.; Smith, K.G.; Shalley, C.E. The interplay between exploration and exploitation. Acad. Manag. J. 2006, 49, 693-706. [CrossRef]

30. Campbell, G.A. Diversification or specialization: The role of risk. Resour. Policy 1990, 16, 293-306. [CrossRef]

31. Santalo, J.; Becerra, M. Competition from specialized firms and the diversification performance linkage. J. Financ. 2008, 63, 851-883. [CrossRef]

32. Brusoni, S.; Prencipe, A.; Pavitt, K. Knowledge, specialization, organizational coupling, and the boundaries of the firm: Why do firms know more than they make? Adm. Sci. Q. 2001, 46, 597-621. [CrossRef]

33. Duysters, G.; Hagedoorn, J. Core competences and company performance in the world-wide computer industry. J. High Tech. Manag. Res. 2000, 11, 75-91. [CrossRef]

34. Katila, R.; Ahuja, G. Something old, something new: A longitudinal study of search behavior and new product introduction. Acad. Manag. J. 2002, 45, 1183-1194.

35. Argyres, N. Capabilities, Technological diversification and divisionalization. Strateg. Manag. J. 1996, 17, 395-410. [CrossRef]

36. Granstrand, O.; Patel, P.; Pavitt, K. Multi-technology corporations: Why they have distributed rather than distinctive core competencies. Calif. Manag. Rev. 1997, 39, 8-25. [CrossRef]

37. Miller, D.J. Technological diversity, related diversification, and firm performance. Strateg. Manag. J. 2006, 27, 601-619. [CrossRef]

38. Leten, B.; Belderbos, R.; Van Looy, B. Technological diversification, coherence, and performance of firms. J. Prod. Innov. Manag. 2007, 24,567-579. [CrossRef]

39. Andriopoulos, C.; Lewis, M.W. Exploitation-exploration tensions and organizational ambidexterity: Managing paradoxes of innovation. Organ. Sci. 2009, 20, 696-717. [CrossRef] 
40. Chen, Y.S.; Chang, C.H.; Lin, Y.H. The Determinants of Green Radical and Incremental Innovation Performance: Green Shared Vision, Green Absorptive Capacity, and Green Organizational Ambidexterity. Sustainability 2014, 6, 7787-7806. [CrossRef]

41. Wan, X.; Cenamor, J.; Parker, G.; Van Alstyne, M. Unraveling Platform Strategies: A Review from an Organizational Ambidexterity Perspective. Sustainability 2017, 9, 734. [CrossRef]

42. Harhoff, D.; Scherer, F.M.; Vopel, K. Citations, family size, opposition and the value of patent rights. Res. Policy 2003, 32, 1343-1363. [CrossRef]

43. Johnstone, N.; Haščič, I.; Poirier, J.; Hemar, M.; Michel, C. Environmental policy stringency and technological innovation: Evidence from survey data and patent counts. Appl. Econ. 2012, 44, 2157-2170. [CrossRef]

44. Graff, G.D. Observing technological trajectories in patent data: Empirical methods to study the emergence and growth of new technologies. Am. J. Agric. Econ. 2003, 85, 1266-1274. [CrossRef]

45. Sakata, J.; Suzuki, K.; Hosoya, J. The analysis of research and development efficiency in Japanese companies in the field of fuel cells using patent data. $R$ D Manag. 2009, 39, 291-304. [CrossRef]

46. Cammarano, A.; Caputo, M.; Lamberti, E.; Michelino, F. R\&D Collaboration Strategies for Innovation: An Empirical Study Through Social Network Analysis. Int. J. Innov. Technol. Manag. 2017, 14, 1-24.

47. Ahuja, G.; Lampert, C.M. Entrepreneurship in the large corporation: A longitudinal study of how established firms create breakthrough inventions. Strateg. Manag. J. 2001, 22, 521-543. [CrossRef]

48. Argote, L. Organizational Learning: Creating, Retaining and Transferring Knowledge, 2nd ed.; Springer: New York, NY, USA, 2013.

49. Fleming, L. Recombinant uncertainty in technological search. Manag. Sci. 2001, 47, 117-132. [CrossRef]

50. Hall, B.H.; Jaffe, A.; Trajtenberg, M. Market Value and Patent Citations: A First Look; NBER: Cambridge, MA, USA, 2000.

51. Cammarano, A.; Michelino, F.; Lamberti, E.; Caputo, M. Accumulated stock of knowledge and current search practices: The impact on patent quality. Technol. Forecast. Soc. 2017, 120, 204-222. [CrossRef]

52. Albert, M.B.; Avery, D.; Narin, F.; McAllister, P. Direct validation of citation counts as indicators of industrially important patents. Res. Policy 1991, 20, 251-259. [CrossRef]

53. Alcácer, J.; Gittelman, M. Patent citations as a measure of knowledge flows: The influence of examiner citations. Rev. Econ. Stat. 2006, 88, 774-779. [CrossRef]

54. Dahlin, K.B.; Behrens, D.M. When is an invention really radical? Defining and measuring technological radicalness. Res. Policy 2005, 34, 717-737. [CrossRef]

55. Lahiri, N. Geographic distribution of R\&D activity: How does it affect innovation quality? Acad. Manag. J. 2010, 53, 1194-1209.

56. Mazzucato, M.; Tancioni, M. R\&D, patents and stock return volatility. J. Evol. Econ. 2012, 22, 811-832.

57. Rosenkopf, L.; Nerkar, A. Beyond local search: Boundary-spanning, exploration, and impact in the optical disk industry. Strateg. Manag. J. 2001, 22, 287-306. [CrossRef]

58. Fleming, L.; Sorenson, O. Science as a map in technological search. Strateg. Manag. J. 2004, 25, 909-928. [CrossRef]

59. Bakker, J.; Verhoeven, D.; Zhang, L.; Van Looy, B. Patent citation indicators: One size fits all? Scientometrics 2016, 106, 187-211. [CrossRef]

60. Cammarano, A.; Caputo, M.; Lamberti, E.; Michelino, F. Open innovation and intellectual property: A knowledge-based approach. Manag. Decis. 2017, 55, 1182-1208. [CrossRef]

61. Al-Ashaab, A.; Flores, M.; Doultsinou, A.; Magyar, A. A balanced scorecard for measuring the impact of industry-university collaboration. Prod. Plan. Control 2011, 22, 554-570. [CrossRef]

62. Kim, C.; Song, J. Creating new technology through alliances: An empirical investigation of joint patents. Technovation 2007, 27, 461-470. [CrossRef] 
63. Arts, S.; Veugelers, R. The Technological Origins and Novelty of Breakthrough Inventions. Available online: https://www.researchgate.net/publication/256051620_The_Technological_Origins_and_ Novelty_of_Breakthrough_Inventions (accessed on 8 August 2019).

64. Michelino, F.; Cammarano, A.; Lamberti, E.; Caputo, M. Open innovation for start-ups: A patent-based analysis of bio-pharmaceutical firms at the knowledge domain level. Eur. J. Innov. Manag. 2017, 20, 112-134. [CrossRef]

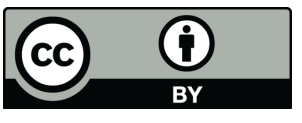

(C) 2019 by the authors. Licensee MDPI, Basel, Switzerland. This article is an open access article distributed under the terms and conditions of the Creative Commons Attribution (CC BY) license (http://creativecommons.org/licenses/by/4.0/). 